Full Length Article

\title{
Effects of teriparatide on hip and upper limb fractures in patients with osteoporosis: A systematic review and meta-analysis
} \author{
Miguel Delgado-Rodríguez ${ }^{g, h}$ \\ a Hospital del Mar-IMIM-UAB, Department of Internal Medicine, Barcelona, Spain \\ b CIBERFES, Institute Carlos III, Barcelona, Spain \\ ${ }^{\mathrm{c}}$ Lilly Research Center, Windlesham, United Kingdom \\ d Department of Clinical Endocrinology, Morbid Obesity and Preventive Medicine, Oslo University Hospital, Norway \\ e University of British Columbia, Vancouver, Canada \\ ${ }^{\mathrm{f}}$ Lilly Research Laboratories, Indianapolis, USA \\ ${ }^{\mathrm{g}}$ Department of Preventive Medicine and Public Health, University of Jaén, Spain \\ ${ }^{\mathrm{h}}$ CIBERESP, Institute Carlos III, Madrid, Spain
}

Adolfo Díez-Pérez ${ }^{\mathrm{a}, \mathrm{b}, *}$, Fernando Marin ${ }^{\mathrm{c}}$, Erik F. Eriksen ${ }^{\mathrm{d}}$, David L. Kendlere, John H. Krege ${ }^{\mathrm{f}}$,

\section{A R T I C L E I N F O}

\section{Keywords:}

Fractures

Hip fracture

Meta-analysis

Systematic review

Teriparatide

\begin{abstract}
A B S T R A C T
In randomized clinical trials (RCTs) with teriparatide, the number of patients with incident hip fractures was small and insufficiently powered to show statistically significant differences between groups. We, therefore, conducted a systematic review and meta-analysis of the efficacy of teriparatide in the reduction of hip and upper limb fractures in women and men with osteoporosis. A comprehensive search of databases until 22 November 2017 was conducted for RCTs of at least 6-month duration that reported non-spine fractures (hip, humerus, forearm, wrist), either as an efficacy or safety endpoint. Only RCTs that included patients with the approved treatment indications and dose for use of teriparatide were included; trials with off-label use of teriparatide were excluded. Two independent reviewers performed study selection and data extraction. Statistical procedures included Peto's method and Mantel-Haenszel with empirical correction, as most of the RCTs reported zero events in at least one of the treatment arms. Study results are expressed as odds ratios (OR) with $95 \%$ confidence intervals (CI). Publication bias and heterogeneity were evaluated with standard statistical tests. Twenty-three RCTs were included, 19 with an active-controlled arm (representing 64.9\% of the patients included in the control group) and 11 double-blind, representing data on 8644 subjects, 3893 of them treated with teriparatide. Mean age (SD) was 67.0 (4.5) years, median treatment duration 18 months (range: 6 to 24 months). A total of 34 incident hip, 31 humerus, 31 forearm, and 62 wrist fractures were included. Meta-analysis results showed an OR $(95 \% \mathrm{CI})$ for hip fractures of $0.44(0.22-0.87 ; \mathrm{p}=0.019)$ in patients treated with teriparatide compared with controls. The effects on the risk of humerus [1.02 (0.50-2.08)], forearm [0.53 (0.26-1.08)] and wrist fractures [1.21 (0.72-2.04)] were not statistically significant ( $p>0.05)$. This meta-analysis provides evidence of efficacy of teriparatide in reducing hip fractures by $56 \%$ in patients with osteoporosis.
\end{abstract}

\section{Introduction}

Typically, osteoporosis randomized control trials have primary endpoints of vertebral fractures, since this is the most frequent fracture experienced in postmenopausal women. Hip fractures are seldom primary endpoints due to their infrequent nature in elderly patients, who are not often recruited to registration clinical trials. The main objective of the pivotal, phase 3 teriparatide studies in patients with postmenopausal osteoporosis was to investigate vertebral anti-fracture efficacy, while phase 4 trials were primarily aimed to investigate the effects on surrogate markers of bone strength and structure in a limited number of patients. Even though many of these studies included subjects at high risk for having osteoporotic fractures, the number of incident hip fractures was relatively small and insufficient to show statistically significant differences between groups. For example, the teriparatide clinical trial with the most hip fractures published to date

\footnotetext{
* Corresponding author at: Department of Internal Medicine, Hospital del Mar-IMIM, Universidad Autónoma Barcelona, Passeig Maritim 25-29, 08003 Barcelona, Spain.

E-mail address: ADiez@parcdesalutmar.cat (A. Díez-Pérez).
} 
reported only 9 such fractures [1], while the pivotal, phase 3 trial of teriparatide in postmenopausal osteoporosis reported only 5 hip fragility fractures between the placebo and the teriparatide $20 \mu \mathrm{g}$ treatment arms [2]. In the largest randomized clinical trial that included a teriparatide treatment arm, only 2 hip fractures were collected in the total clinical trial cohort [3].

However, results from non-controlled, observational studies with larger patient cohorts, suggest that teriparatide may reduce the risk of hip fractures [4-7]. Understanding the effects of treatment of teriparatide on hip fractures is important given the clinical impact and health economic importance of this type of fractures, and the lack of data from individual randomized clinical trials adequately powered to evaluate the efficacy of this drug on hip fractures.

The primary aim of this systematic review and meta-analysis was to evaluate the efficacy of teriparatide in the reduction of hip fractures in women and men with osteoporosis. The secondary objective was the investigation of the effects of teriparatide on upper limb fractures (i.e. humerus, forearm and wrist), in order to evaluate the fracture results in non-weight bearing bones.

\section{Material and methods}

\subsection{Literature search strategy}

We designed this study according to the Preferred Reporting Items for Systematic Reviews and Meta-Analysis Guidelines [8]. The protocol was registered in the International Prospective Register of Systematic Reviews, PROSPERO (registration number: CRD42018085635).

A comprehensive search strategy aimed to identify RCTs that reported non-spine fractures either as an efficacy or safety endpoint, published in English, French or Spanish until 22 November 2017. Literature searches on MEDLINE (OVID interface, 1948 onwards) and EMBASE (OVID interface, 1974 onwards) were performed. Keywords were identified with medical subject headings (MeSH) and text words related to "teriparatide" and "parathyroid hormone (1-34)". Additional sources included searches in clinical trial repositories (clinicaltrials.gov and EUDRAC), and contact with main authors and manufactures that owned study reports of clinical trials on teriparatide that missed some fracture site details in the peer-reviewed publications.

\subsection{Selection criteria}

The main outcome of interest was the incidence of fragility, low trauma hip fractures following teriparatide treatment. Eligible studies met the following inclusion criteria: (1) RCTs with study participants treated according to the approved indications for the use of teriparatide in the USA, Europe and Japan (i.e.; postmenopausal and male osteoporosis, glucocorticoid-induced osteoporosis); (2) minimum of 6-month treatment exposure; (3) a maximum treatment duration as approved (i.e.; 24 months), at the approved dose (20 $\mu \mathrm{g}$ /day subcutaneously) [9], and (4) controlled with placebo or other active anti-osteoporosis drug, either commercially available, or under clinical development. Narrative reviews, observational studies, comments, opinion pieces, methodological reports, editorials, and letters were excluded. Reviews were screened to check for potential additional studies that were not published as standalone papers.

Following the screening of titles and abstracts, duplicates were removed. If multiple reports were available from the same study, fracture data from the most recent report were included. Two authors (ADP and FM) independently analyzed the titles and abstracts and then performed the study selection and evaluation of quality and data extraction of the full papers. Discrepancies were resolved by consensus between the reviewer authors.

\subsection{Data extraction and management}

Data extracted from each study included participants, interventions, description of the comparators, and outcomes with the following specific items: first author, reference, year of publication, control group, participants' characteristics [gender, age], study design, clinical development phase, incident selected non-vertebral fractures, type of fracture endpoint (efficacy or safety), and duration of treatment. In the case of forearm and wrist fractures, the fracture site term was kept as reported in the original publication; fractures reported at the "radius" were included in the forearm fractures analysis, while fractures reported at "carpal bones" were included in the wrist fractures analysis. The lack of detailed results of other individual non-vertebral fracture sites in most of the publications precluded a pooled analysis of all nonvertebral fractures.

For consistency with the primary objective, we focused the analysis on low trauma, fragility upper limb fractures when that information was explicitly disclosed in the publications.

\subsection{Quality assessment}

The scale recommended by the Cochrane Collaboration [10] was used to assess the methodological quality of identified studies as well as the risk of bias of the individual included. The major criteria of the checklist were randomization, double blind (both patients and researcher/assessor), comparability of treatment groups, available followup information and equal treatment used for treatment groups. Each criterion might be answered in three ways: yes (adequate information), no (inadequate information), or unclear information.

\subsection{Data synthesis and statistical analysis}

As it was expected that many studies would report zero fractures in at least one of the treatment arms, two procedures were applied to estimate the risk of fracture: odds ratio (OR) by the Peto's method and Mantel-Haenszel with empirical correction, with 95\% confidence intervals (CI) [11]. Differences were considered statistically significant when p-value was $<0.05$. If there were more than two comparators in the same trial, the results of the comparators were pooled initially, and separated in sensitivity analysis (placebo and active comparators). A random effects model was not considered a priori, as heterogeneity is very uncommon when the data are sparse. Statistical heterogeneity was tested using the Q test (significance level: 0.1$)$ and $I^{2}$ statistic $(0 \%$ to 40\%: might not be important; $30 \%$ to $60 \%$ : may represent moderate heterogeneity; $50 \%$ to $90 \%$ : may represent substantial heterogeneity; $75 \%$ to $100 \%$ : considerable heterogeneity). Meta-regression procedures were applied to ascertain whether mean age and duration of trial had an influence on the risk of fracture. An assessment for publication bias was performed with a visual inspection of funnel plot asymmetry and also by Egger weighted regression tests [12,13].

A pre-planned sensitivity analysis was performed by removing the two clinical trials that did not report the hip fracture details in the peerreviewed publications, but in clinical study reports filed by the studies sponsor $[14,15]$.

Analyses were performed using the Stata 15 statistical package (College Station, TX, USA).

\subsection{Subgroup analysis}

To address heterogeneity among study populations, pre-specified subgroup analyses were performed as follows: type of comparator (placebo or active-treatment osteoporosis drug), type of randomization (double-blind or open-label), patient characteristics (age and gender) and follow-up period duration. 


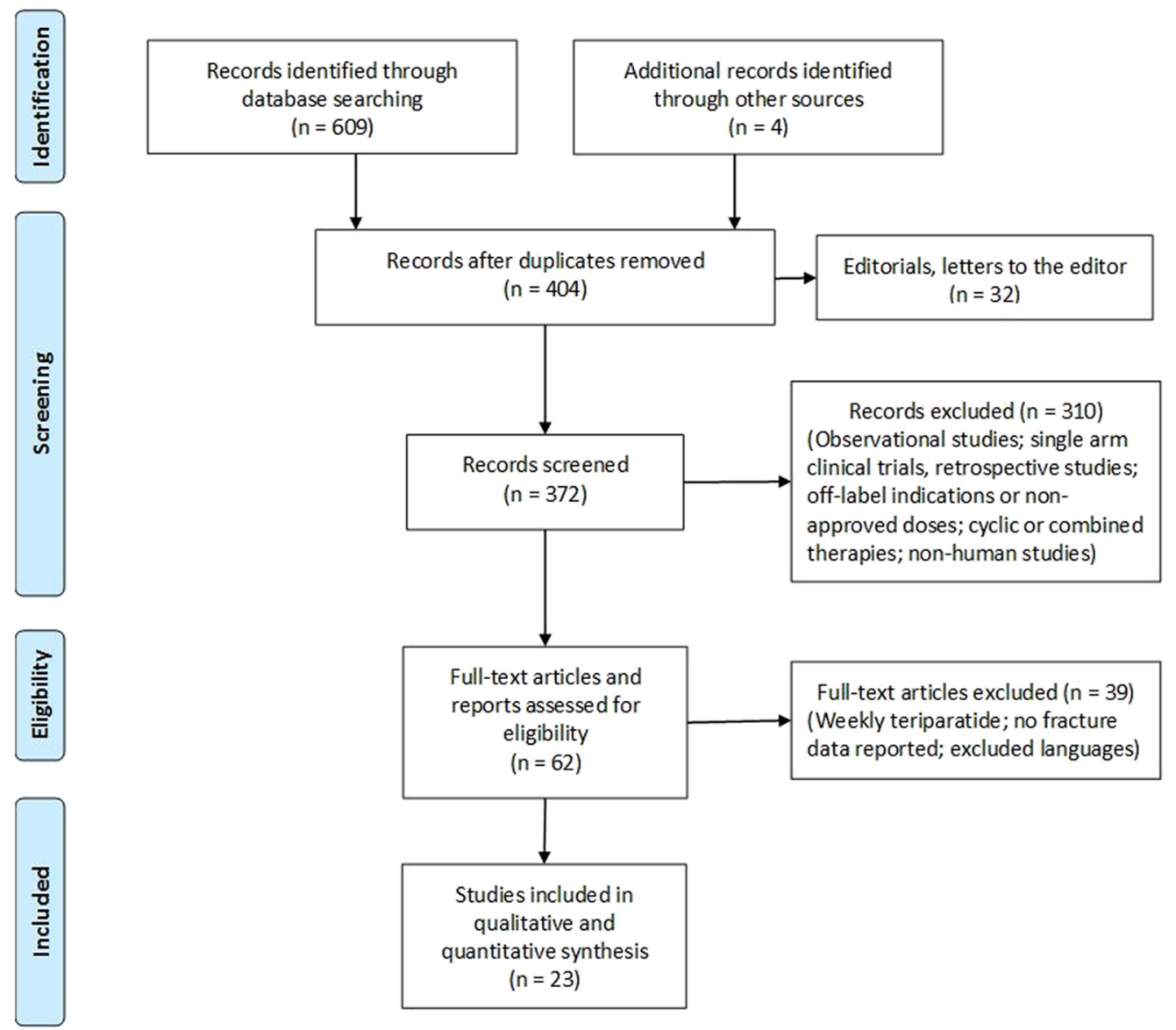

Fig. 1. Study selection flow diagram (preferred reporting items for systematic reviews and meta-analysis).

\section{Results}

\subsection{Summary of searches and study selection process}

A total of 609 citations were identified through searches plus 4 onfile clinical trial reports, of which 404 records remained after removal of duplicates. After screening via titles and abstracts, 372 articles and study reports remained for further evaluation. Following further evaluation, 310 more articles were excluded for the following reasons: not a RCT, off-label use of teriparatide, non-approved doses, testing of combination therapies with other anti-osteoporosis drugs, or they were non-human studies. In many instances, more than one exclusion criteria applied. Sixty-two records remained for full-text assessment, 39 of them were further excluded because the index drug was weekly teriparatide, no fracture results were included, or they were published in languages other than English, French or Spanish. Therefore, a total of 23 clinical trials published between 2001 and 2017 were included in the current meta-analysis (Fig. 1).

Detailed information of the included studies is summarized in Table 1. Twenty-three RCTs were included, representing data on 8644 subjects, 3893 of them treated with teriparatide. Eight trials were double-blind during the full study follow-up [2,14,16-21], 12 openlabel [3,22-33], and 3 trials had a mixed design with an initial doubleblind phase ( 6 to 12 months duration) followed by an open-label phase for up to 18 to 24 months [1,15,34] (Table 1). There were 4 placebocontrolled trials $[2,15,16,18], \quad 17$ active-controlled trials [1,14,17,19-34], one three-arm study [3], and one multiple-arm study [31], where teriparatide was used open-label as an active comparator in randomized clinical trials of abaloparatide and romosozumab respectively. The active-comparators were risedronate [1,19-21,24,28], alendronate [14,26,31], zoledronic acid [27,34], calcitonin [22,23], strontium ranelate [25], denosumab [29,30,32], abaloparatide [3] and romosozumab [31,33]. In the control group, 1667 (35.1\%) patients received placebo and 3084 (64.9\%) patients an active comparator (Table 2). Seventeen studies were of women with postmenopausal osteoporosis, 3 studies included exclusively men [16,20,28], and 3 studies included a mixed population of men and women $[1,14,15]$ (Table 1$)$. Of all subjects, there were 545 men $(6.3 \%$ of the total subjects) (Table 1$)$. Two studies were of patients with glucocorticoid-induced osteoporosis $[14,28]$ for a total of 520 patients $(6.0 \%$ of the total included subjects). Overall, subjects' mean age (SD) was 67.0 (4.5) years, and the median teriparatide treatment duration was 18 months (range: 6 to 24 months).

\subsection{Risk of bias assessment}

All included studies had a low risk of bias according to randomization, allocation concealment, and comparability of intervention groups at the beginning of the trial and equal treatment of intervention groups (Supplemental Table 1). No evidence of publication bias was detected using funnel plot or Egger's test (intercept $=0.94$; $95 \% \mathrm{CI}$ : -3.00 to $1.12, \mathrm{p}=0.315$ ).

\subsection{Pooled estimate of the effect of teriparatide on hip and upper limb bones fractures}

A total of 34 incident hip, 31 humerus, 31 forearm, and 62 wrist fractures were reported (Table 2). In 14 studies, representing 1651 patients, no hip fractures were reported [16-18,20,22-27,29-32,34] (Table 1). Meta-analysis results showed an OR (95\% CI) for hip fractures of $0.44(0.22-0.87 ; p=0.019)$ in patients treated with teriparatide compared with controls (Fig. 2). The effects on the risk of humerus [OR (95\%CI): 1.02 (0.50-2.08)], forearm [OR (95\%CI): 0.53 
Table 1

Characteristics of the included RCTs of teriparatide and hip and upper limb fractures included in the meta-analysis.

\begin{tabular}{|c|c|c|c|c|c|c|c|c|c|c|}
\hline Study alias & Patients (n) & $\begin{array}{l}\text { Study } \\
\text { population }\end{array}$ & Mean age & Males (\%) & Comparator(s) & Trial design & $\begin{array}{l}\text { Main study } \\
\text { endpoint }\end{array}$ & $\begin{array}{l}\text { Type of } \\
\text { fracture } \\
\text { endpoint }\end{array}$ & $\begin{array}{l}\text { Trial duration } \\
\text { (months) }\end{array}$ & $\begin{array}{l}\text { Trial } \\
\text { phase }\end{array}$ \\
\hline Neer 2001 [2] & 1085 & PMW & 69.0 & 0 & Placebo & DB & VFx & Efficacy & 21 & 3 \\
\hline Hadji 2012 [19] & 710 & PMW & 71.0 & 0 & Risedronate & DB & Back pain & Efficacy & 18 & $3 b$ \\
\hline Malouf 2017 [1] & 216 & PMW and men & 76.8 & 22.8 & Risedronate & $\mathrm{DB}+\mathrm{OL}$ & BMD & Safety & 18 & 4 \\
\hline Glüer 2013 [28] & 92 & GIO & 56.3 & 100 & Risedronate & OL & BMD & Safety & 18 & $3 b$ \\
\hline Kendler 2018 [21] & 1360 & PMW & 72.1 & 0 & Risedronate & $\mathrm{DB}$ & VFx & Efficacy & 24 & 4 \\
\hline Miller 2016 [3] & 2463 & PMW & 68.8 & 0 & Placebo/Abaloparatide & $\mathrm{OL}$ & VFx & Efficacy & 18 & 3 \\
\hline $\begin{array}{l}\text { Leder } 2014 \\
{[29,30]}\end{array}$ & 64 & PMW & 65.9 & 0 & Denosumab & OL & BMD & Safety & 24 & 4 \\
\hline Cosman 2011 [27] & 275 & PMW & 65.0 & 0 & Zoledronic Acid & OL & BMD & Safety & 12 & 4 \\
\hline $\begin{array}{l}\text { Dempster } 2016 \\
{[34]}\end{array}$ & 69 & PMW & 64.5 & 0 & Zoledronic Acid & $\mathrm{DB}+\mathrm{OL}$ & Biopsy & Safety & 24 & 4 \\
\hline Kung 2006 [22] & 104 & PMW & 70.6 & 0 & Calcitonin & OL & BMD & Safety & 6 & 4 \\
\hline Recker 2009 [25] & 79 & PMW & 64.6 & 0 & Strontium & OL & Biopsy & Safety & 6 & 4 \\
\hline Walker 2013 [20] & 19 & Men & 52.8 & 100 & Risedronate & DB & BMD & Safety & 18 & 4 \\
\hline $\begin{array}{l}\text { Dempster } 2016 \\
\text { [32] }\end{array}$ & 69 & PMW & 63.4 & 0 & Denosumab & OL & Biopsy & Safety & 6 & 4 \\
\hline Saag 2007 [14] & 428 & $\begin{array}{l}\text { PMW and men } \\
\text { GIO }\end{array}$ & 56.7 & 19.4 & Alendronate & DB & BMD & Safety & 18 & 3 \\
\hline $\mathrm{M}_{\mathrm{c}}$ Clung 2005 & 203 & PMW & 66.0 & 0 & Alendronate & $\mathrm{DB}$ & BMD & Safety & 18 & 3 \\
\hline Orwoll 2003 [16] & 298 & Men & 59.0 & 100 & Placebo & DB & BMD & Safety & 11 & 3 \\
\hline $\begin{array}{l}\text { Miyauchi } 2010 \\
\text { [15] }\end{array}$ & 203 & PMW and men & 69.6 & 7 & Placebo & $\mathrm{DB}+\mathrm{OL}$ & BMD & Safety & 24 & 3 \\
\hline $\mathrm{M}_{\mathrm{c}}$ Clung 2014 & 206 & PMW & 66.7 & 0 & $\begin{array}{l}\text { Placebo/Alendronate/ } \\
\text { Romosozumab }^{\mathrm{a}}\end{array}$ & $\mathrm{OL}$ & BMD & Safety & 12 & 2 \\
\hline Panico 2011 [26] & 81 & PMW & 62.5 & 0 & Alendronate & OL & BMD & Safety & 18 & 4 \\
\hline $\begin{array}{l}\text { Miyauchi } 2008 \\
\text { [18] }\end{array}$ & 77 & PMW & 70.7 & 0 & Placebo & DB & BMD & Safety & 6 & 2 \\
\hline $\begin{array}{l}\text { Anastasilakis } 2008 \\
{[24]}\end{array}$ & 44 & PMW & 65.1 & 0 & Risedronate & OL & BMD & Safety & 12 & 4 \\
\hline Hwang 2006 [23] & 63 & PMW & 67.5 & 0 & Calcitonin & OL & BMD & Safety & 6 & 4 \\
\hline $\begin{array}{l}\text { Langdahl } 2017 \\
\text { [33] }\end{array}$ & 436 & PMW & 71.5 & 0 & Romosozumab & $\mathrm{OL}$ & BMD & Safety & 12 & 3 \\
\hline
\end{tabular}

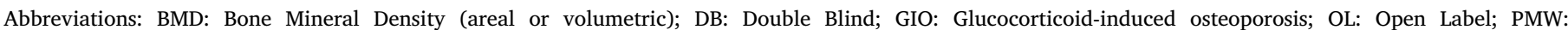
Postmenopausal women; VFx: Vertebral Fractures.

${ }^{\text {a }}$ Only the romosozumab $210 \mathrm{mg}$ once monthly arm was included to match the phase 3 trials selected dose.

(026-1.08)] and wrist fractures [OR (95\%CI): $1.21(0.72-2.04)]$ were not statistically significant ( $\mathrm{p}>0.05$ ) (Fig. 3a-c). The effect on the risk of combined upper limb fractures was non-significant [OR $(95 \% \mathrm{CI})$ : $0.94(0.65-1.35)]$ ( $\mathrm{p}>0.05$ ) or by type of comparator (Supplemental Fig. S3).

In a subgroup analysis based on the type of comparator (placebo or active), a significant risk reduction for hip fractures was observed in the placebo stratum [OR (95\%CI): $0.20(0.05-0.81) ; \mathrm{p}=0.024$; heterogeneity Chi-squared: $\left.0.73, I^{2}=0.0 \%(\mathrm{p}=0.694)\right]$, but not in the active-comparator stratum [OR (95\%CI): $0.54(0.25-1.17) ; \mathrm{p}=0.118$; heterogeneity Chi-squared: 5.71, $\left.I^{2}=12.5 \% \quad(\mathrm{p}=0.335)\right]$ (Supplemental Fig. S1). The analysis of the hip fracture results by study blinding (double-blind vs open-label) showed a borderline non-significant reduction in both strata: the ORs (95\% CI) were 0.50 [(0.24-1.03); $\mathrm{p}=0.059]$ for the double-blind, and 0.44 [(0.22-0.87); $\mathrm{p}=0.089]$ for the open-label strata (Supplemental Fig. S2). The nonstatistical differences for the individual upper limb fracture sites remained similar in these subgroups analyses (data not included), with the exception of a statistical significant increased OR for wrist fractures in the analysis of teriparatide versus active comparators [OR (95\%CI): 1.93 (1.02-3.65); $\mathrm{p}=0.045]$.

There was no indication for a relationship between fracture risk reduction and patients' age or the clinical trial duration. Analysis by gender was not feasible given the low number of hip fractures in male subjects $(\mathrm{n}=1)$.

After removing the 2 hip fractures that were not described in the in the peer-reviewed papers [14,15], but which were included in the clinical study reports, the hip fracture risk remained statistically reduced [OR (95\%CI): $0.49(0.24-0.98) ; \mathrm{p}=0.045$; heterogeneity Chisquared: $\left.5.92, I^{2}=0.0 \%(\mathrm{p}=0.432)\right]$.

\section{Discussion}

Our meta-analysis based on 8644 subjects enrolled in 23 randomized, controlled clinical trials of $>6$-month duration, shows that teriparatide $20 \mu \mathrm{g}$ per day reduces the risk of hip fractures by $56 \%$ after a median treatment duration of 18 months. The analysis of the upper limb bones fractures showed neutral effects of teriparatide on the risk of fractures in these non-weight bearing bones.

These results complement previous meta-analysis that has shown the statistically significant efficacy of teriparatide in reducing the risk of vertebral and non-vertebral fractures in postmenopausal women with osteoporosis [35-39]. Our findings of the hip fracture efficacy also confirms previous results by Murad et al. [38] who reported in a network meta-analysis, combining direct and indirect estimates, that teriparatide had the highest probability (42\%) of being ranked as most effective and had the highest reduction in the risk of hip fracture (OR, 0.42). However, the review by Murad et al. [38] included several studies with non-approved teriparatide doses for the treatment of osteoporosis (40 and $100 \mu \mathrm{g} /$ day), and only 4 of the 23 RCTs that we have included in the present systematic review were analyzed.

The findings of this meta-analysis are consistent with several other lines of evidence suggesting that teriparatide is likely to reduce the risk of hip fractures, including that teriparatide increases cancellous bone volume, improves bone architecture, and increases cortical thickness associated with increased cortical remodeling at the hip [4,40], which 
Table 2

Sample size and number of hip, humerus, forearm and wrist fractures for each study included in the meta-analysis.

\begin{tabular}{|c|c|c|c|c|c|c|c|c|c|c|c|}
\hline Study alias & Comp(s) & TPTD (n) & $\begin{array}{l}\text { Hip } \\
\text { TPTD (n) }\end{array}$ & $\begin{array}{l}\text { Humerus } \\
\text { TPTD (n) }\end{array}$ & $\begin{array}{l}\text { Forearm } \\
\text { TPTD (n) }\end{array}$ & $\begin{array}{l}\text { Wrist } \\
\text { TPTD (n) }\end{array}$ & $\begin{array}{l}\text { COMP } \\
(\mathrm{S})(\mathrm{n})\end{array}$ & $\begin{array}{l}\text { Hip } \\
\text { COMP (n) }\end{array}$ & $\begin{array}{l}\text { Humerus } \\
\text { COMP (n) }\end{array}$ & $\begin{array}{l}\text { Forearm } \\
\text { COMP (n) }\end{array}$ & $\begin{array}{l}\text { Wrist } \\
\text { COMP (n) }\end{array}$ \\
\hline Neer 2001 [2] & Placebo & 541 & 1 & 2 & NR & 2 & 544 & 4 & 2 & NR & 7 \\
\hline Hadji 2012 [19] & Risedronate & 360 & 5 & 4 & $0^{\mathrm{a}}$ & 4 & 350 & 2 & 5 & $4^{\mathrm{a}}$ & 2 \\
\hline Malouf 2017 [1] & Risedronate & 106 & 2 & 1 & $1^{\mathrm{a}}$ & 0 & 110 & 7 & 1 & $0^{\mathrm{a}}$ & 0 \\
\hline Glüer 2013 [28] & Risedronate & 45 & 0 & 0 & 0 & 0 & 47 & 1 & 0 & 1 & 0 \\
\hline Kendler 2018 [21] & Risedronate & 680 & 2 & 4 & 6 & 2 & 680 & 5 & 2 & 10 & 1 \\
\hline Miller 2016 [3] & $\begin{array}{l}\text { Placebo/ } \\
\text { Abaloparatide }\end{array}$ & 818 & 0 & 2 & 0 & 17 & $821 / 824$ & $2 / 0$ & $3 / 1$ & $4 / 1$ & $15 / 7$ \\
\hline $\begin{array}{r}\text { Leder } 2014 \\
{[29,30]}\end{array}$ & Denosumab & 31 & 0 & NR & NR & NR & 33 & 0 & NR & NR & NR \\
\hline Cosman 2011 [27] & Zoledronic Acid & 138 & 0 & 0 & 0 & 1 & 137 & 0 & 1 & 0 & 2 \\
\hline $\begin{array}{l}\text { Dempster } 2016 \\
\text { [34] }\end{array}$ & Zoledronic Acid & 34 & 0 & NR & NR & NR & 35 & 0 & NR & NR & NR \\
\hline Kung 2006 [22] & Calcitonin & 47 & 0 & 0 & 0 & 0 & 57 & 0 & 0 & 0 & 0 \\
\hline Recker 2009 [25] & Strontium & 39 & 0 & 0 & 0 & 0 & 40 & 0 & 0 & 0 & 0 \\
\hline Walker 2013 [20] & Risedronate & 9 & 0 & 0 & 0 & 0 & 10 & 0 & 0 & 0 & 0 \\
\hline $\begin{array}{l}\text { Dempster } 2016 \\
\text { [32] }\end{array}$ & Denosumab & 33 & 0 & NR & NR & NR & 36 & 0 & NR & NR & NR \\
\hline Saag $2007\left[^{[14]^{\mathrm{a}}}\right.$ & Alendronate & 214 & 0 & 0 & 1 & 0 & 214 & 1 & 0 & 0 & 0 \\
\hline $\mathrm{M}_{\mathrm{c}}$ Clung 2005 & Alendronate & 102 & 0 & 0 & 0 & 1 & 101 & 0 & 0 & 0 & 0 \\
\hline Orwoll 2003 [16] & Placebo & 151 & 0 & 0 & 1 & 0 & 147 & 0 & 0 & 0 & 0 \\
\hline $\begin{array}{c}\text { Miyauchi } 2010 \\
{[15]^{\mathrm{a}}}\end{array}$ & Placebo & 136 & 0 & 1 & 0 & 0 & 67 & 1 & 1 & 1 & 0 \\
\hline $\mathrm{M}_{\mathrm{c}}$ Clung 2014 & $\begin{array}{l}\text { Placebo/Alendronate/ } \\
\text { Romosozumab }\end{array}$ & 54 & 0 & 0 & 0 & 0 & $\begin{array}{l}50 / 51 / \\
51\end{array}$ & $0 / 0 / 0$ & $0 / 0 / 0$ & $0 / 0 / 0$ & $0 / 0 / 1$ \\
\hline Panico 2011 [26] & Alendronate & 42 & 0 & 0 & 0 & 0 & 39 & 0 & 0 & 0 & 0 \\
\hline $\begin{array}{c}\text { Miyauchi } 2008 \\
\text { [18] }\end{array}$ & Placebo & 39 & 0 & 0 & 0 & 0 & 38 & 0 & 0 & 0 & 0 \\
\hline $\begin{array}{l}\text { Anastasilakis } 2008 \\
\text { [24] }\end{array}$ & Risedronate & 22 & 0 & 0 & 0 & 0 & 22 & 0 & 0 & 0 & 0 \\
\hline Hwang 2006 [23] & Calcitonin & 34 & 0 & 0 & 0 & 0 & 29 & 0 & 0 & 0 & 0 \\
\hline $\begin{array}{c}\text { Langdahl } 2017 \\
\text { [33] }\end{array}$ & Romosozumab & 218 & 0 & 1 & 1 & 0 & 218 & 1 & 0 & 0 & 0 \\
\hline Total & & 3893 & 10 & 15 & 10 & 27 & 4751 & 24 & 16 & 21 & 35 \\
\hline
\end{tabular}

COMP(S): Comparator(s); NR: Not Reported; TPTD: Teriparatide.

${ }^{a}$ Fracture Data: Lilly Data on File.

results in improved biomechanical properties [41]. Additionally, teriparatide $20 \mu \mathrm{g}$ /day increased femoral neck and total hip BMD during ongoing treatment through 24 months [42]. Also, an analysis of the Direct Assessment of Nonvertebral Fractures in Community Experience
(DANCE) observational study of 4085 men and women treated with teriparatide for 24 months, showed the rate of hip fractures decreased as treatment duration increased [4]. Finally, the real-world experience of teriparatide in reducing the risk of fractures showed hip fractures

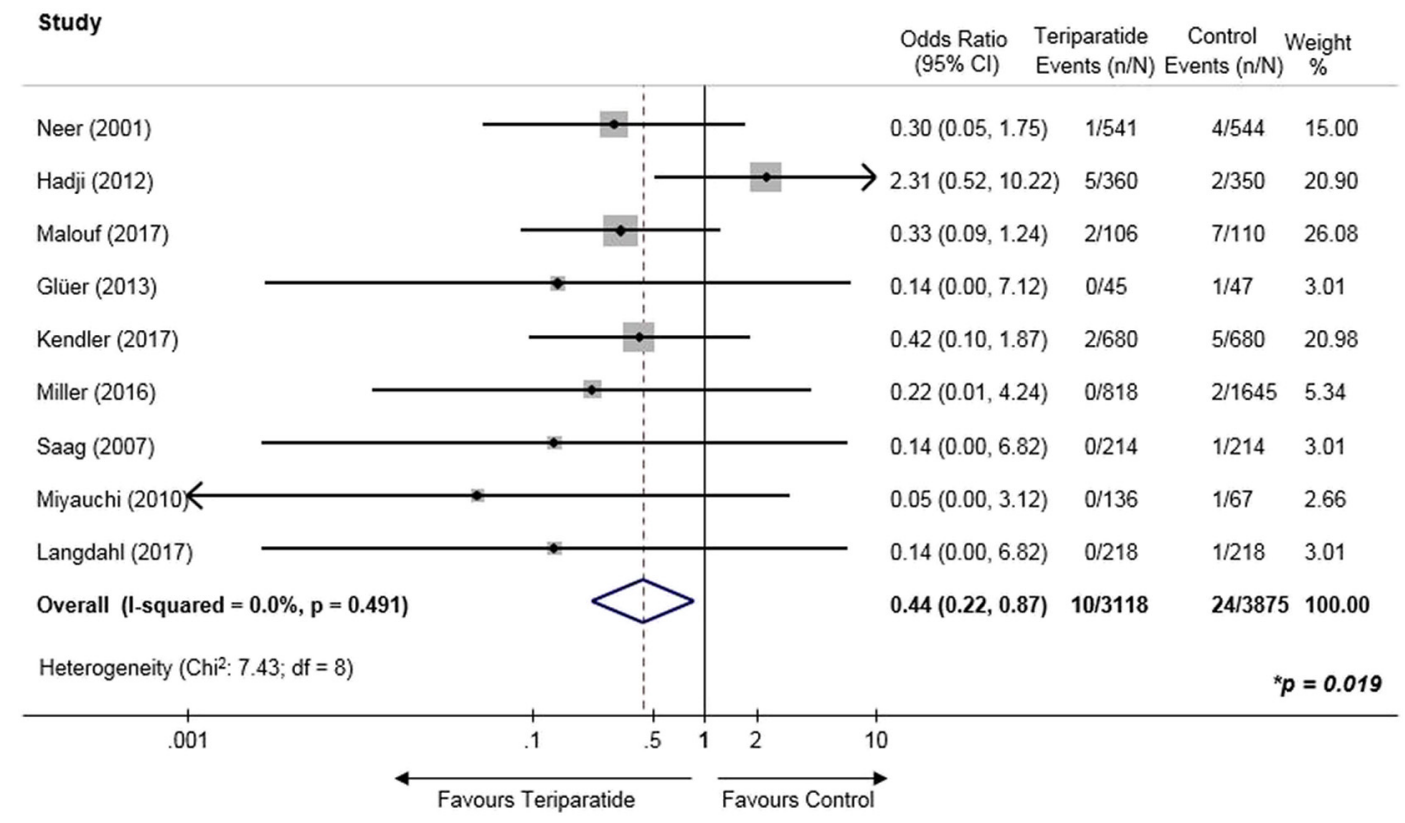

Fig. 2. Forest plot of hip fracture outcomes. 

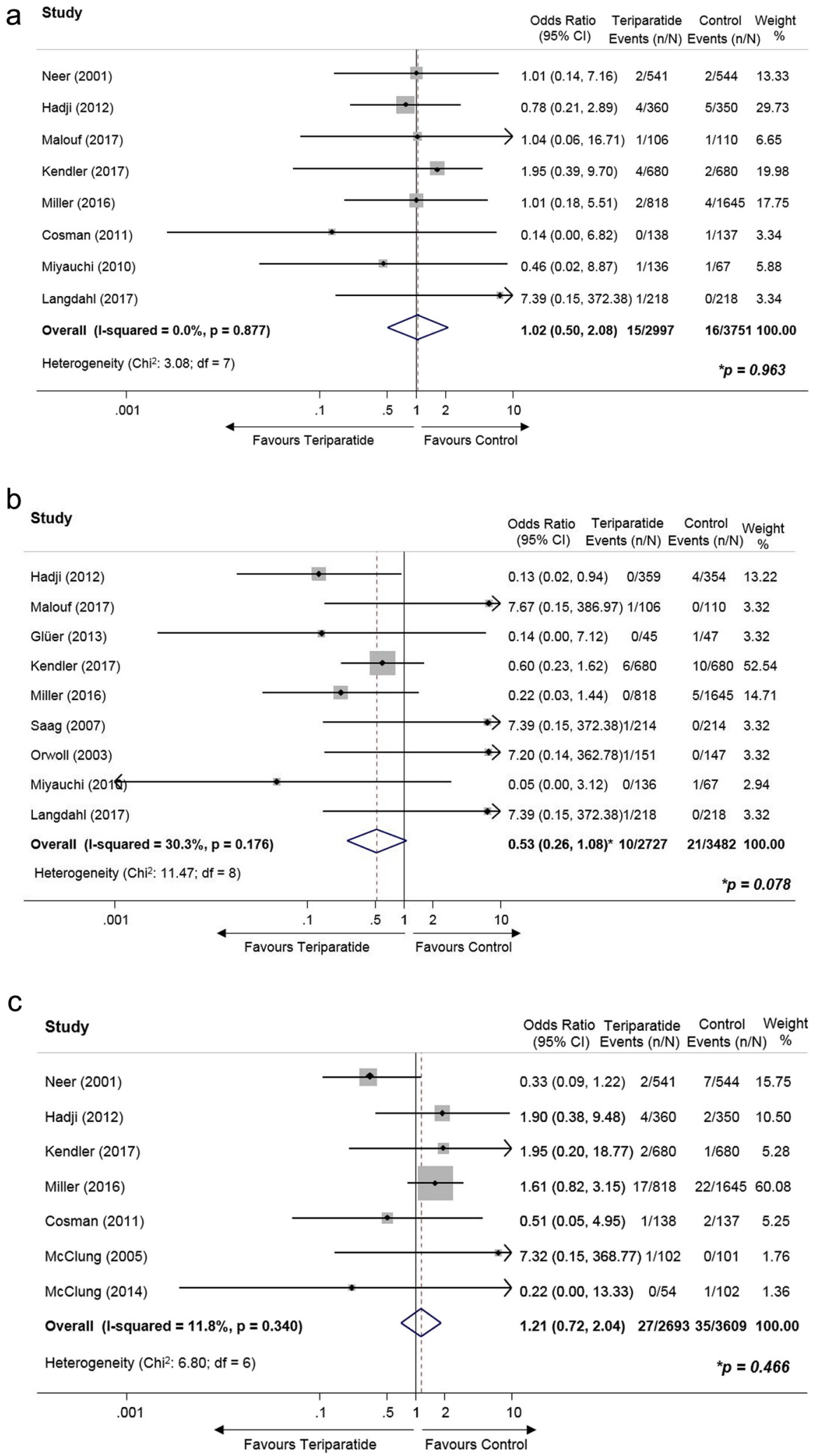

Fig. 3. Forest plots of upper limb fracture outcomes: (a) humerus, (b) forearm, (c) wrist.

decreased as adherence and persistence to teriparatide treatment increased [6].

Of note, the hip fracture efficacy with teriparatide was detected after a relatively short median treatment duration of 18 months, with a maximum treatment duration in the included studies of 24 months. The pivotal trial for teriparatide [2] was discontinued early because of safety concerns raised by preclinical findings of increased risk of osteosarcoma in rats [43], precluding the completion of the planned 3year treatment duration, and the likely accumulation of higher numbers of hip fractures. The approved maximum duration of teriparatide treatment of 24 months is shorter than for other osteoporosis treatments, which limits the ability to show hip fracture efficacy in 
individual clinical trials. Therefore, the demonstration of hip antifracture efficacy in this meta-analysis is important and clinically relevant information since reduction in hip fracture risk is one of the major efficacy outcomes for osteoporosis treatments because of their associated morbidity, mortality and socioeconomic burden.

Previous studies have shown that teriparatide induces a transient, early decrease in bone density at the proximal femur in patients pretreated with antiresorptive drugs [33,44,45]. Imaging and histological studies show increased cortical porosity in patients initiating teriparatide therapy, probably reflecting increased cortical bone remodeling $[46,47]$. Although none of these studies show increased hip fracture risk, this finding has been a concern for some clinicians [48]. Our study helps to clarify that teriparatide was not associated with any long-term safety issues regarding cortical-rich fracture sites, rather the opposite. However, the meta-analytical approach did not permit an evaluation of the time course of this reduction. Similarly, cortical bone mineral density loss at the distal radius $[2,49]$ has also been a concern. However, our meta-analysis showed a neutral effect on forearm and wrist fractures overall.

This meta-analysis has some limitations. The total number of hip fractures $(n=34)$ is small, however, the number of fractures we collected in the teriparatide intervention arm $(n=10)$ vs. the comparator arms $(n=24)$ was similar to that in the alendronate pivotal FIT-I trial ( $n=11$ in alendronate and $n=22$ hip fractures in placebo) [50], but lower than in other pivotal studies including the HORIZON trial for zoledronate ( $\mathrm{n}=140$ hip fractures) [51], the FREEDOM trial for denosumab ( $\mathrm{n}=70$ hip fractures) [52], and the HIP trial for risedronate ( $n=101$ hip fractures) [53]. These trials were, however, of longer treatment duration (2.9 years in FIT-I, and 3 years in the other studies), and were compared with placebo. In the present meta-analysis, however, 19 out of the 23 analyzed clinical trials had one or two active comparator arms with several drugs that have already shown antifracture efficacy at the hip, representing $64.9 \%$ of the patients included in the control group, that might have decreased the effect size of teriparatide in the results. Another limitation is that we pool clinical trials of postmenopausal women, men, and patients on glucocorticoid therapy where the risk for hip fractures may be different. Finally, we were unable to do a systematic review of other individual non-vertebral fracture sites given the incomplete reporting in most of the studies. In fact, in only 4 of the 23 included clinical trials, were non-vertebral fractures analyzed as an efficacy endpoint, while in most of them these fractures were reported as adverse events in the safety section.

The strength of this review is its comprehensive nature, including randomized, controlled trials with active comparators or placebo at the approved teriparatide dose in the approved indications for its use. This approach reduced the potential risk of recall and selection bias. We assessed four fracture outcomes: hip, humerus, forearm and wrist. This is the first systematic analysis of the efficacy of teriparatide at individual fracture sites of the upper limb.

\section{Conclusions}

Our systematic review and individual-level meta-analyses of 23 randomized clinical trials comparing teriparatide to placebo or other anti-osteoporosis drugs in a total of 8644 subjects with osteoporosis in the approved indications for its clinical use, indicate that there is a significant reduction of hip fracture and a neutral effect on the pooled upper limb fractures reported. Collectively, these results support consideration of teriparatide for the treatment of osteoporosis as a first-line therapy in patients at high risk for osteoporotic fractures, although they should be interpreted in the context of the relatively small number of reported hip fractures.

Supplementary data to this article can be found online at https:// doi.org/10.1016/j.bone.2018.09.020.

\section{Founding source}

This study was supported by Lilly. Lilly manufactures and commercializes teriparatide.

\section{Declaration of interest}

Dr. Díez-Pérez received honoraria, consultancies and/or research funding from Amgen, UCB, Roche, Mereo, Lilly and owns shares of Active Life Scientific. Dr. Eriksen received speaker and consulting fees from Lilly, Amgen, Merck, Pfizer, EffRx and IDS. Dr. Kendler received honoraria, consultancies, and/or research funding from Lilly, Amgen, Astra-Zeneca and Pfizer. Drs. F. Marin and J.H. Krege are employees and shareholders of Lilly. Dr. Delgado-Rodríguez has nothing to disclose.

\section{Author roles}

Dr. Díez-Pérez, Dr. Marin and Prof. Delgado-Rodríguez designed the study. Dr. Díez-Pérez and Dr. Marin searched literature databases and performed the selection of studies and data collection. Prof. DelgadoRodríguez made the statistical analyses of the data. Dr. Díez-Pérez and Dr. Marin wrote the first manuscript draft. All authors interpreted the results, reviewed and approved the final manuscript. Prof. DelgadoRodríguez takes responsibility for the integrity of the data analysis.

\section{Acknowledgments}

The authors would like to thank Yolanda Moreno, Department of Medical Information, Lilly Europe, for her support in the bibliographic search. The authors thank, Andrea Rossi of International Scientific Communications, Lilly, for providing medical writing and editorial support, in accordance with Good Publication Practice (GPP3) guidelines.

\section{References}

[1] J. Malouf-Sierra, U. Tarantino, P.A. García-Hernández, et al., Effect of teriparatide or risedronate in elderly patients with a recent pertrochanteric hip fracture: final results of a 78-week randomized clinical trial, J. Bone Miner. Res. 32 (5) (2017) 1040-1051.

[2] R.M. Neer, C.D. Arnaud, J.R. Zanchetta, et al., Effect of parathyroid hormone (1-34) on fractures and bone mineral density in postmenopausal women with osteoporosis, N. Engl. J. Med. 344 (19) (2001) 1434-1441.

[3] P.D. Miller, G. Hattersley, B.J. Riis, et al., Effect of Abaloparatide vs placebo on new vertebral fractures in postmenopausal women with osteoporosis: a randomized clinical trial, JAMA 316 (7) (2016) 722-733.

[4] E.F. Eriksen, T.M. Keaveny, E.R. Gallagher, J.H. Krege, The effects of teriparatide therapy at the hip in patients with osteoporosis, Bone 67 (2014) 246-256.

[5] D.P. Beall, R.G. Feldman, M.L. Gordon, et al., Patients with prior vertebral or hip fractures treated with teriparatide in the direct assessment of nonvertebral fractures in community experience (DANCE) observational study, Osteoporos. Int. 27 (2016) 1191-1198.

[6] R.T. Burge, D.P. Disch, S. Gelwicks, X. Zhang, J.H. Krege, Hip and other fragility fracture incidence in real-world teriparatide-treated patients in the United States, Osteoporos. Int. 28 (2017) 799-809.

[7] S.L. Silverman, K.G. Saag, B. Langdahl, et al., Hip and other fracture risk in patients receiving teriparatide in real-world clinical practice: pooled data from four prospective observational studies, Osteoporos. Int. (Suppl. 1) (2017) (OC36).

[8] L. Shamseer, D. Moher, M. Clarke, et al., Preferred reporting items for systematic review and meta-analysis protocols (PRISMA-P) 2015: elaboration and explanation, Br. Med. J. g7647 (2015) 349.

[9] US Food and Drugs Administration, FORTEO. Prescribing Information, Available at: https://www.accessdata.fda.gov/drugsatfda_docs/label/2013/021318s036lbl.pdf, (2018), Accessed date: 6 March 2018

[10] J.P.T. Higgins, D.G. Altman, P.C. Gøtzsche, et al., The Cochrane Collaboration's tool for assessing risk of bias in randomised trials, Br. Med. J. 343 (2011) 889-893.

[11] M.J. Sweeting, A.J. Sutton, P.C. Lambert, What to add to nothing? Use and avoidance of continuity corrections in meta-analysis of sparse data, Stat. Med. 23 (9) (2004) 1351-1375.

[12] M. Egger, G.D. Smith, M. Schneider, et al., Bias in meta-analysis detected by a simple, graphical test, Br. Med. J. 315 (7109) (1997) 629-634.

[13] J.L. Peters, A.J. Sutton, D.R. Jones, K.R. Abrams, L. Rushton, Comparison of two methods to detect publication bias in meta-analysis, JAMA 295 (6) (2006) 676-680. 
[14] K.G. Saag, E. Shane, S. Boonen, et al., Teriparatide or alendronate in glucocorticoidinduced osteoporosis, N. Engl. J. Med. 357 (20) (2007) 2028-2039.

[15] A. Miyauchi, T. Matsumoto, T. Sugimoto, M. Tsujimoto, M.R. Warner, T. Nakamura, Effects of teriparatide on bone mineral density and bone turnover markers in Japanese subjects with osteoporosis at high risk of fracture in a 24-month clinical study: 12-month, randomized, placebo-controlled, double-blind and 12-month open-label phases, Bone 47 (2010) 493-502.

[16] E.S. Orwoll, W.H. Scheele, S. Paul, et al., The effect of teriparatide [human parathyroid hormone (1-34)] therapy on bone density in men with osteoporosis, J. Bone Miner. Res. 18 (2003) 9-17.

[17] M.R. McClung, J.S. Martin, P.D. Miller, et al., Opposite bone remodeling effects of teriparatide and alendronate in increasing bone mass, Arch. Intern. Med. 165 (2005) 1762-1768.

[18] A. Miyauchi, T. Matsumoto, H. Shigeta, M. Tsujimoto, D. Thiebaud, T. Nakamura, Effect of teriparatide on bone mineral density and biochemical markers in Japanese women with postmenopausal osteoporosis: a 6-month dose-response study, J. Bone Miner. Metab. 26 (2008) 624-634.

[19] P. Hadji, J.R. Zanchetta, L. Russo, et al., The effect of teriparatide compared with risedronate on reduction of back pain in postmenopausal women with osteoporotic vertebral fractures, Osteoporos. Int. 23 (2012) 2141-2150.

[20] M.D. Walker, N.E. Cusano, J. Sliney, et al., Combination therapy with risedronate and teriparatide in male osteoporosis, Endocrine 44 (2013) 237-246.

[21] D.L. Kendler, F. Marin, C.A.F. Zerbini, et al., Effects of teriparatide and risedronate on new fractures in post-menopausal women with severe osteoporosis (VERO): a multicentre, double-blind, double-dummy, randomised controlled trial, Lancet 391 (2018) 230-240.

[22] W.C. Kung, E.G. Pasion, M. Sofiyan, et al., A comparison of teriparatide and calcitonin therapy in postmenopausal Asian women with osteoporosis: a 6-month study, Curr. Med. Res. Opin. 22 (2006) 929-937.

[23] J.S. Hwang, S.T. Tu, T.S. Yang, J.F. Chen, C.J. Wang, K.S. Tsai, Teriparatide vs. calcitonin in the treatment of Asian postmenopausal women with established osteoporosis, Osteoporos. Int. 17 (2006) 373-378.

[24] A.D. Anastasilakis, D.G. Goulis, S.A. Polyzos, et al., Head-to-head comparison of risedronate vs, teriparatide on bone turnover markers in women with postmenopausal osteoporosis: a randomised trial, Int. J. Clin. Pract. 62 (2008) 919-924.

[25] R.R. Recker, F. Marin, S. Ish-Shalom, et al., Comparative effects of teriparatide and strontium ranelate on bone biopsies and biochemical markers of bone turnover in postmenopausal women with osteoporosis, J. Bone Miner. Res. 24 (2009) $1358-1368$.

[26] A. Panico, G.A. Lupoli, F. Marciello, et al., Teriparatide vs. alendronate as a treatment for osteoporosis: changes in biochemical markers of bone turnover, BMD and quality of life, Med. Sci. Monit. 17 (2011) CR442-R448.

[27] F. Cosman, E.F. Eriksen, C. Recknor, et al., Effects of intravenous zoledronic acid plus subcutaneous teriparatide [rhPTH(1-34)] in postmenopausal osteoporosis, J. Bone Miner. Res. 26 (2011) 503-511.

[28] C.C. Glüer, F. Marin, J.D. Ringe, et al., Comparative effects of teriparatide and ri sedronate in glucocorticoid-induced osteoporosis in men: 18-month results of the EuroGIOPs trial, J. Bone Miner. Res. 28 (2013) 1355-1368.

[29] J.N. Tsai, A.V. Uihlein, H. Lee, et al., Teriparatide and denosumab, alone or combined, in women with postmenopausal osteoporosis: the DATA study randomised trial, Lancet 382 (9886) (2013) 50-56.

[30] B.Z. Leder, J.N. Tsai, A.V. Uihlein, et al., Two years of denosumab and teriparatide administration in postmenopausal women with osteoporosis (the DATA extension study): a randomized controlled trial, J. Clin. Endocrinol. Metab. 99 (2014) 1694-1700.

[31] M.R. McClung, A. Grauer, S. Boonen, et al., Romosozumab in postmenopausal women with low bone mineral density, N. Engl. J. Med. 370 (5) (2014) 412-420.

[32] D.W. Dempster, H. Zhou, R.R. Recker, et al., Differential effects of teriparatide and denosumab on intact PTH and bone formation indices: AVA osteoporosis study, J. Clin. Endocrinol. Metab. 101 (2016) 1353-1363.

[33] B.L. Langdahl, C. Libanati, D.B. Crittenden, et al., Romosozumab (sclerostin monoclonal antibody) versus teriparatide in postmenopausal women with osteoporosis transitioning from oral bisphosphonate therapy: a randomised, open-label, phase 3 trial, Lancet 390 (2017) 1585-1594.

[34] D.W. Dempster, P. Roschger, B.M. Misof, et al., Differential effects of teriparatide and zoledronic acid on bone mineralization density distribution at 6 and 24 month in the SHOTZ study, J. Bone Miner. Res. 31 (2016) 1527-1535.

[35] P. Vestergaard, N.R. Jorgensen, L. Mosekilde, P. Schwarz, Effects of parathyroid hormone alone or in combination with antiresorptive therapy on bone mineral density and fracture risk - a meta-analysis, Osteoporos. Int. 18 (2007) 45-57.

[36] R.B. Hopkins, R. Goeree, E. Pullenayegum, et al., The relative efficacy of nine osteoporosis medications for reducing the rate of fractures in post-menopausal women, BMC Musculoskelet. Disord. 12 (2011) 209 http://www.biomedcentral. com/1471-2474/12/209.

[37] S.-L. Han, S.-L. Wan, Effect of teriparatide on bone mineral density and fracture in postmenopausal osteoporosis: meta-analysis of randomised controlled trials, Int. J. Clin. Pract. 66 (2012) 199-209.

[38] M.H. Murad, M.T. Drake, R.J. Mullan, et al., Comparative effectiveness of drug treatments to prevent fragility fractures: a systematic review and network metaanalysis, J. Clin. Endocrinol. Metab. 97 (2012) 1871-1880.

[39] T. Saito, J.M. Sterbenz, S. Malay, L.Z. Zhong, M.P. MacEachern, K.C. Chung, Effectiveness of anti-osteoporotic drugs to prevent secondary fragility fractures: systematic review and meta-analysis, Osteoporos. Int. 28 (2017) 3289-3300.

[40] K.E.S. Poole, G.M. Treece, G.R. Ridgway, P.M. Mayhew, J. Borggrefe, A.H. Gee, Targeted regeneration of bone in the osteoporotic human femur, PLoS One 6 (1) (2011) e16190, , https://doi.org/10.1371/journal.pone.0016190.

[41] J. Borggrefe, C. Graeff, T.N. Nickelsen, F. Marin, C.C. Glüer, Quantitative computed tomographic assessment of the effects of 24 months of teriparatide treatment on 3D femoral neck bone distribution, geometry, and bone strength: results from the EUROFORS study, J. Bone Miner. Res. 25 (2010) 472-481.

[42] R. Lindsay, J.H. Krege, F. Marin, L. Jin, J.J. Stepan, Teriparatide for osteoporosis: importance of the full course, Osteoporos. Int. 27 (2016) 2395-2410.

[43] J.L. Vahle, M. Sato, G.G. Long, et al., Skeletal changes in rats given daily subcutaneous injections of recombinant human parathyroid hormone (1-34) for 2 years and relevance to human safety, Toxicol. Pathol. 30 (2002) 312-321.

[44] B.M. Obermayer-Pietsch, F. Marin, E.V. McCloskey, et al., Effects of two years of daily teriparatide treatment on BMD in postmenopausal women with severe osteoporosis with and without prior antiresorptive treatment, J. Bone Miner. Res. 23 (2008) 1591-1600.

[45] B.Z. Leder, J.N. Tsai, A.V. Uihlein, et al., Denosumab and teriparatide transitions in postmenopausal osteoporosis (the DATA-switch study): extension of a randomised controlled trial, Lancet 386 (2015) 1147-1155.

[46] E. Seeman, T.J. Martin, Co-administration of antirsorptive and anabolic agents: a missed opportunity, J. Bone Miner. Res. 30 (2015) 753-764.

[47] E.F. Eriksen, J.P. Brown, Concurrent administration of PTH and antiresorptives: additive effects or DXA cosmetics, Bone 86 (2016) 139-142.

[48] C. Crandall, Parathyroid hormone for treatment of osteoporosis, Arch. Intern. Med. 162 (2002) 2297-2309.

[49] J.N. Tsai, A.V. Uihlein, S.M. Burnett-Bowie, et al., Effects of two years of teriparatide, denosumab, or both on bone microarchitecture and strength (DATAHRpQCT study), J. Clin. Endocrinol. Metab. 101 (2016) 2023-2030.

[50] D.M. Black, S.R. Cummings, D.B. Karpf, et al., Randomised trial of effect of alendronate on risk of fracture in women with existing vertebral fractures. Fracture Intervention Trial Research Group, Lancet 348 (1996) 1535-1541.

[51] D.M. Black, P.D. Delmas, R. Eastell, et al., Once-yearly zoledronic acid for treatment of postmenopausal osteoporosis, N. Engl. J. Med. 356 (2007) 1809-1822.

[52] S.R. Cummings, J. San Martin, M.R. McClung, et al., Denosumab for prevention of fractures in postmenopausal women with osteoporosis, N. Engl. J. Med. 361 (2009) $756-765$.

[53] M.R. McClung, P. Geusens, P.D. Miller, et al., Effect of risedronate on the risk of hip fracture in elderly women. Hip Intervention Program Study Group, N. Engl. J. Med. 344 (2001) 333-340. 